\title{
Echocardiographic photorealistic imaging of leiomyomatosis intravascularis
}

\author{
Paweł Czub $^{1} \cdot$ Monika Budnik ${ }^{1}\left[\right.$ [ $\cdot$ Franciszek Majstrak $^{1} \cdot$ Janusz Kochanowski $^{1} \cdot$ Piotr Hendzel $^{1} \cdot$ Grzegorz Opolski $^{1}$
}

Received: 14 July 2020 / Accepted: 21 July 2020 / Published online: 2 August 2020

(c) The Author(s) 2020

\begin{abstract}
We present a case of patient with leiomyomatosis intravascularis. To diagnose, we used 3D photorealistic imaging which allowed us better visualisation of pathological structures as well as planning the surgical procedure in greater detail. The main advantage of this technique is the possibility to move the virtual light source and thus visualize the specific part of the heart.
\end{abstract}

Keywords 3D echocardiography $\cdot$ Photorealistic imaging $\cdot$ Right atrial tumour

A 39 year old female patient was admitted to the hospital on suspicion of additional mass in the right atrium (RA). 2 weeks before, she underwent surgery to remove the tumours of the uterus and the bladder.

Transthoracic echocardiography confirmed the presence of inhomogeneous and mobile mass in the RA (Fig. 1a). Moreover, the inferior vena cava (IVC) was also involved. We decided to perform transesophageal echocardiography (TEE) which showed that the structure protruds across the tricuspid valve throughout the cardiac cycle (Fig. 1b). Using the latest display method, the Philips cardiac TrueVue 3D photorealistic imaging, we could see in detail a huge mass that was elongated, mobile, inhomogeneous, with no adhesion to the wall of the heart and the veins and vibrating along with the heartbeat (Fig. 1c, d, Supplemental Videos).
The patient underwent a surgery, whereby a huge mass of about $30 \mathrm{~cm}$ in length was excised through RA on beating heart with cardiopulmonary bypass (Fig. 1e). Following the surgery, a histopathological examination diagnosed leiomyomatosis.

The use of 3D photorealistic imaging enables not only to better visually identify pathological structures, but also plan the surgical procedure in greater detail. Its main advantage over 3D echo is that it enables to move the virtual light source and thus visualize the specific part of the heart, especially the prosthetic valves and additional masses in the heart.

Electronic supplementary material The online version of this article (https://doi.org/10.1007/s10554-020-01951-0) contains supplementary material, which is available to authorized users.

Monika Budnik

moni.budnik@gmail.com

1 Medical University of Warsaw, Warsaw, Poland 


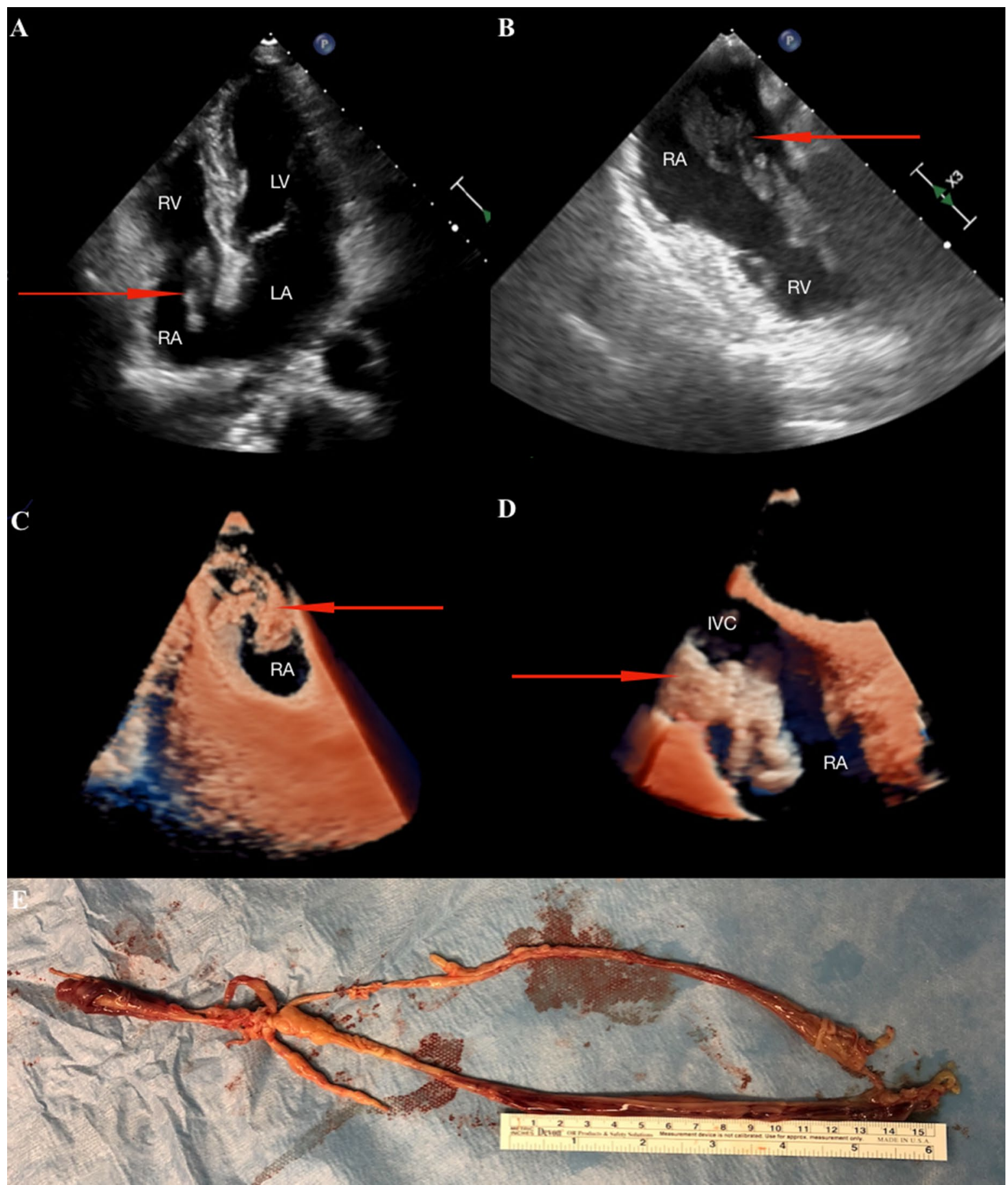

Fig. 1 a TTE; 2D four chamber view; b TEE; 2D two chamber view; c, d TEE, 3D photorealistic imaging; e removed structure from RA and IVC. Arrows show the mass in the RA and IVC. IVC inferior vena cava, $L A$ left atrium, $L V$ left ventricle, $R A$ right atrium, $R V$ right ventricle

\section{Compliance with ethical standards}

Conflict of interest There is no conflict of interest among authors.
Open Access This article is licensed under a Creative Commons Attribution 4.0 International License, which permits use, sharing, adaptation, distribution and reproduction in any medium or format, as long as you give appropriate credit to the original author(s) and the source, provide a link to the Creative Commons licence, and indicate if changes were made. The images or other third party material in this article are 
included in the article's Creative Commons licence, unless indicated otherwise in a credit line to the material. If material is not included in the article's Creative Commons licence and your intended use is not permitted by statutory regulation or exceeds the permitted use, you will need to obtain permission directly from the copyright holder. To view a copy of this licence, visit http://creativecommons.org/licenses/by/4.0/.
Publisher's Note Springer Nature remains neutral with regard to jurisdictional claims in published maps and institutional affiliations. 